MATEC Web of Conferences 11,01032 (2014)

DOI: $10.1051 /$ matecconf / 20141101032

(C) Owned by the authors, published by EDP Sciences, 2014

\title{
Studying the effect of thermal and acid exposure on alkali activated slag Geopolymer
}

\author{
H.M.KHATER, * \\ *Housing and Building National Research Centre (HBNRC) \\ 87 El-Tahreer St., Dokki, Giza, P.O. Box 1770 Cairo \\ E-Mail:Hkhater4@yahoo.com
}

\begin{abstract}
This article reports a study about thermal stability as well as acid resistance of geopolymer materials prepared from Ground Granulated Blast Furnace Slag (GGBFS), Air Cooled Slag (ACS), Silica fume (SF) and cement kiln dust (CKD) using 6\% (weight) of equal mix from alkaline sodium hydroxide and sodium silicate activators. Study of addition of ACS, SF and CKD as partial replacement of GGBFS is investigated so as to improve the mechanical and microstructural properties of geopolymer mixes. Compressive strength and SEM were utilized in these studies. Materials were prepared using water/binder of 0.30 at $38^{\circ} \mathrm{C}$ and $100 \% \mathrm{RH}$. Results showed that geopolymer materials prepared using alkali activated slag exhibit large changes in compressive strength with increasing the firing temperature from 300 to $1000^{\circ} \mathrm{C}$ and exhibit an enhancement in thermal stability as compared to concrete specimens. Materials prepared by replacing GGBFS by $15 \%$ ACS resist thermal deterioration up to $1000^{\circ} \mathrm{C}$. It was suggested to be suitable for refractory insulation applications as well as for production of nuclear concrete reactors. On the other hand, geopolymer mixes exhibit low stability upon subjecting to different concentration from the mix of nitric and hydrochloric acid in equal ratio (1:1). Current studies of geopolymer microstructure were focused on the morphology as well as the relationship between compositions and mechanical properties.
\end{abstract}

Keywords: Environment, Materials processing, Microstructure, thermal, acid

\section{Introduction}

Recently discovered geopolymers that are produced by alkaline activation of aluminosilicate raw materials, which are transformed into reaction products by polymerization in a high $\mathrm{pH}$ environment and hydrothermal conditions at relatively low temperatures (up to $120^{\circ} \mathrm{C}$ ). This binder has a great potential as an environmentally favourable alternative to Portland cement. It can produce binder with advantages of Portland cement with a lower cost and a large reduction in $\mathrm{CO}_{2}$ emissions using industrial waste materials. Examples of this binder type include Class $F$ fly ash (low calcium fly ash) based geopolymer (FFG) [Palomo, et al. (1999), Khale and Chaudhary (2007), Duxson et al. (2007)], and alkali-activated slag cement (AAS) [Song and Jennings (1999)]. Because of low production energy requirements from common raw materials and their inflammability at high temperatures, these compounds attract increasing interest as environmentally friendly, fire proof building materials, materials for encapsulating hazardous wastes for storage or disposal and also used as sound as well as heat insulators [Davidovits et al., (1994), Lyon et al. (1996)].

GGBS has been used in composite cements and as a cementitious component of concrete for many years and it can be expected that prolonged uses of GGBS will continue for the foreseeable future. On the other hand alkali-activated slag cements using granulated blast-furnace slags were invented by Glukhovsky (1980) and patented in 1958. Alkali activated slags have been employed on a limited scale as oil well cements and as a roof support system in mine applications in South Africa and Canada. Industrial experience of precast products utilizing these cements is widespread in Eastern Europe, Finland and France [Talling and Brandstetr (1989)]. The use of slag as supplementary cementitious material improves concrete durability as it reduces the permeability of GGBS concrete and significantly inhibits the ingress of sulfates [Osborne (1991)]. The 
reduction in chloride penetration achieved by GGBS has been confirmed by many different investigators [Pal et al. (2002)]. CKD on the other hand with its fine-grained and high alkali content can be considered as an excellent activator for pozzolanic materials. The dissolution rate of materials with latent pozzolanic properties such as blast furnace slag generally depends on the alkali concentration of the reacting system [Wang, et al. (1995)].

Previous investigations by Davidovits et al. (1994), Barbosa and MacKenzie (2003) reported very good heat resistant properties of materials prepared using sodium silicate, potassium silicate and metakaolin, having thermal stability up to 1200 $1400^{\circ} \mathrm{C}$. Krivenko and Kovalchuk (2002) investigated heat resistant of geopolymer materials manufactured using class $\mathrm{F}$ fly ash, which had good thermal resistance properties up to $800^{\circ} \mathrm{C}$. Geopolymers prepared using alumino-silicate materials (fly ash, slag, metakaolin, etc.,) have framework structures originating from condensation of tetrahedral aluminosilicate units of varying $\mathrm{Al} / \mathrm{Si}$ ratio such as $(\mathrm{Al}-\mathrm{O}-\mathrm{Si}-\mathrm{O}-) \mathrm{M}^{+},(\mathrm{Al}-\mathrm{O}-\mathrm{Si}-\mathrm{O}-\mathrm{Si}-\mathrm{O}-$ ) $\mathrm{M}^{+},(\mathrm{Si}-\mathrm{O}-\mathrm{Al}-\mathrm{O}-\mathrm{Si}-\mathrm{O}-\mathrm{Si}-\mathrm{O}-) \mathrm{M}^{+}$etc. $\mathrm{M}^{+}$is an alkali ion, typically $\mathrm{Na}$ or $\mathrm{K}$, which balances the charge of the tetrahedral Al [Davidovits (1994a)].

Geopolymer cement is also acid-resistant, because unlike the Portland cement, geopolymer cement does not rely on lime and not dissolved by acidic solutions. As shown by the tests of exposing the specimens to $5 \%$ of sulfuric acid and chloric acid, geopolymer cements were relatively stable with the weight lose in the range of 5-8\%; while the Portland based cements were destroyed and the calcium alumina cement lost weight about 30-60\% [Davidovits (1994b)]. Some published papers [Bakharev (2005), Gourley and Johnson (2005), Song et al. (2005)] also reported results of the tests on acid resistance of geopolymers and geopolymer concrete. By observing the weight loss after acid exposure, these researchers concluded that geopolymers or geopolymer concrete is superior to Portland cement concrete in terms of acid resistance as the weight loss is much lower. Bakharev et al.(2003) has also observed that there is a degradation in the compressive strength of test specimens after acid exposure and the rate of degradation depended on the period of exposure. Glukhovsky (1980) showed that the strength of AAS mortars increased after 1 year in $1-2 \% \mathrm{MgSO}_{4}$ solution and stayed constant for 2 years in dilute acids, $\mathrm{HCl}$ and $\mathrm{H}_{2} \mathrm{SO}_{4}$, while OPC samples deteriorated in six months. Douglas et al. (1992) reported AAS concrete having good resistance to chloride ion penetration with ion penetration ranging from 1311 to $2547 \mathrm{C}$ for 28 days curing and from 676 to $1831 \mathrm{C}$ at 91 days.
The objective of the current study is to investigate the effect partial substitution of GGBFS by ACS, SF and CKD and estimate their stability upon firing at different temperatures from 300 $1000^{\circ} \mathrm{C}$ for $2 \mathrm{hrs}$ with a heating rate of $5^{\circ} \mathrm{C} / \mathrm{min}$ by mapping examination using SEM and measuring their compressive strength with temperature change. Also, study the impact of equal mix of nitric and hydrochloric acids at different concentrations (2, 4 and 6molars) on geopolymer behaviour and compare their stability with normal concrete specimens that prepared at the same experimental condition. Also, elucidate the optimum geopolymer mix from water cooled slag, air cooled slag, SF and cement dust upon fire and acid conditions, while focusing on the morphology as well as its relationship between compositions and mechanical properties.

\section{Experimental procedures}

\subsection{Materials}

Materials used in this investigation are water cooled slag (known as ground granulate blast furnace slag (GGBFS)) as well as air cooled slag (ACS) sourced from Iron and Steel Factory-Helwan, Egypt. Silica fume from Suez cement company (Helwan plant). Cement kiln by-pass dust (CKD) from BeniSuef Cement Factory, Egypt.

Two different alkali activators are used sodium silicate solution and sodium hydroxide. Sodium hydroxide $(\mathrm{NaOH})$ brought from SHIDO Company with purity of $99 \%$ and liquid sodium silicate (LSS) purchased from Fisher Company consists of $32 \% \mathrm{SiO}_{2}$ and $17 \% \mathrm{Na}_{2} \mathrm{O}$ with Silica modulus $\mathrm{SiO}_{2} / \mathrm{Na}_{2} \mathrm{O}$ equal 1.88 and density $1.46 \mathrm{~g} / \mathrm{cm}^{3}$ ( $\mathrm{Na}_{2} \mathrm{SiO}_{3} \cdot 9 \mathrm{H}_{2} \mathrm{O}$ ). Analytic grade concentrated nitric and hydrochloric acid for acid resistance testing in order to prepare 2, 4 and 6 molars in an equal ratio.

Ordinary Portland cement from Helwan Company, Egypt, fine sand $(<1.0 \mathrm{~mm})$ from Oases (Wahat)-Road, Egypt and coarse aggregate composites with a maximum aggregate size of 14 $\mathrm{mm}$ for concrete formation as a way of comparison with the produced geopolymer composite. Chemical composition of the starting raw materials was illustrated in Table (1).

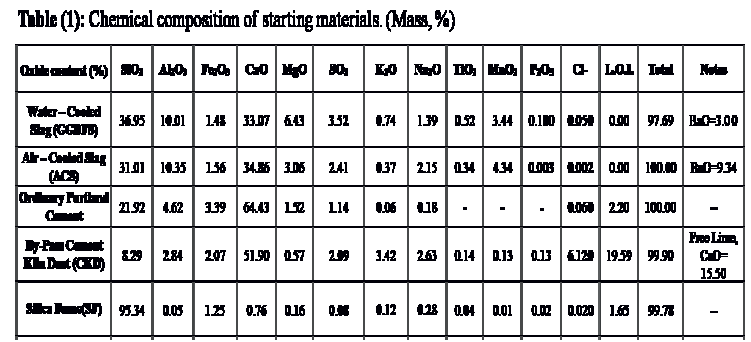


Mineralogical composition of starting raw materials are shown in Figure (1), and illustrating the amorphous structure GGBFS, while ACS is completely crystalline. On the other hand CKD composed mainly of calcite $(\mathrm{CaCO} 3)$, sylvite $(\mathrm{KCl})$ and halite $(\mathrm{NaCl})$ in a decreasing order.

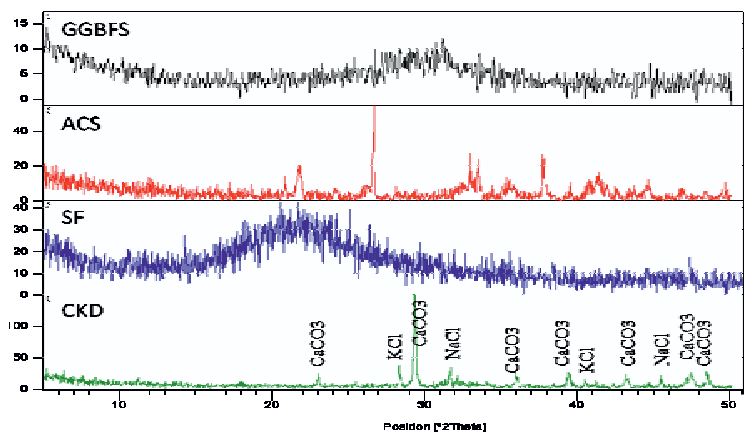

Fig.(1): Mineralogical composition of starting raw materials.

\subsection{Geopolymerization and curing}

Geopolymers were made by hand-mixing raw materials of each mixture passing a sieve of $90 \mu \mathrm{m}$ as represented in Table (2) with the alkaline solution for $10 \mathrm{~min}$ and a further $5 \mathrm{~min}$ using mixer. All investigations involved using of $\mathrm{Na}_{2} \mathrm{SiO}_{3}$ and $\mathrm{NaOH}$ in the ratio of $3: 3 \mathrm{wt} . \%$ of dry mixes, respectively, except mix that contains cement dust; this ratio was chosen based on previous investigations [El-Sayed et al. (2011), Abd.El-Aziz (2010)]. Water-binder ratio $(\mathrm{w} / \mathrm{b})$ was 0.30 by mass. Paste mixtures were cast into $25 \times 25 \times 25 \mathrm{~mm}$ cubic-shaped moulds vibrated for compaction and sealed with a lid to minimize any loss of evaporable water. On the other hand, concrete mix was performed using coarse aggregate, fine aggregate and cement in the ratio of $4: 2: 1$, respectively, using water content of 0.30 for better comparison with geopolymer mixes.

Table 2: Composition of the gcoplymer mixcs.(Mass, \%)

\begin{tabular}{|c|c|c|c|c|}
\hline Mix no. & $\begin{array}{c}\text { Water cooled } \\
\text { slag(WCS) }\end{array}$ & $\begin{array}{c}\text { Air cooled } \\
\text { slag(ACS) }\end{array}$ & $\begin{array}{c}\text { Silica fume } \\
\text { (SF) }\end{array}$ & $\begin{array}{c}\text { Cement kiln } \\
\text { dust (ckd) }\end{array}$ \\
\hline 1 & 90 & - & 10 & - \\
\hline 2 & 85 & 15 & - & - \\
\hline 3 & 75 & 25 & - & - \\
\hline 4 & 25 & 50 & - & 25 \\
\hline
\end{tabular}

All mixes were left to cure undisturbed under ambient temperature for 24 hours, and then subjected to curing temperature of $38^{\circ} \mathrm{C}$ under $100 \%$ relative humidity (R.H.). At the end of the curing regime, the specimens were subjected to compressive strength measurements and then the resulted crushed specimens were subjected to stopping of the hydration process using stopping solution of alcohol/acetone (1:1) followed by washing with acetone as recommended by different investigators [Saikia et al. (2004)]; to prevent further hydration and for further analysis followed by drying of crushed specimens for 24 hours at $80^{\circ} \mathrm{C}$, and then preserved in a well tight container until time of testing. Concrete specimens were prepared as a way of comparison under the same condition using coarse aggregate $(14 \mathrm{~mm})$ : sand $(<1.0 \mathrm{~mm})$ : cement in the ratio of $4: 2: 1$, respectively.

Firing resistant measurement was done by curing at $38^{\circ} \mathrm{C}$ and $100 \%$ R.H. for 28 days. The samples were calcined at different temperatures $\left(300-1000^{\circ} \mathrm{C}\right)$ for 2 hours with a heating rate of $5^{\circ} \mathrm{C} / \mathrm{min}$ [Wenying et al., (2008)]. Acid-resistant performance: samples were cured in $38^{\circ} \mathrm{C}$ for 7 days. After that the samples were soaked in a solution of hydrochloric acid and nitric acid in an equal ratio using a concentrations of $2 \& 4$ and 6 molars up to testing time while acid solution will changed periodically every month so as to retain concentration constant as possible [Wenying et al., (2008)].

\subsection{Methods of investigation}

Chemical analysis was carried out using Axios, WD-XRF Sequential Spectrometer (Panalytical, Netherland, 2009) The X-ray diffraction (XRD) analysis was carried out using a Philips PW 1050/70 diffractometer; the data were identified according to the XRD software (pdf-2 database on CD Release 2005. Compressive strength tests were carried out using five tones German Brüf pressing machine with a loading rate of $100 \mathrm{~kg} / \mathrm{min}$ determined according to ASTM-C109 (2007). Microstructure of the hardened alkali activated slag geopolymer was studied using SEM Inspect S (FEI Company, Netherland) equipped with an energy dispersive X-ray analyzer (EDX). The removal of free water was accomplished by using alcohol/acetone method as recommended by different investigators [Saikia et al. (2004)].

\section{Results and discussions}

\subsection{Fire resistance of slag geopolymer}

Scanning electron microscope of alkali activated GGBFS mix specimens that is partially replaced by $10 \% \mathrm{SF}$, fired at different firing temperatures are shown in Fig.(2). Morphology of fire untreated specimen (Fig.2a) exhibits a pronounced homogeneous microstructure giving an indication about dissolving most of aluminosilicate materials forming monomer, oligomer and polymeric three dimensional structure network forming an 
amorphous geopolymer composition. It is also noticed the coexistence of hydration materials (CSH) with geopolymer network forming a tough and well compacted structure which will be positively reflected on the mechanical strength of this mixture. Heating at $500^{\circ} \mathrm{C}$, SF-specimen did not experience large change in its topography in spite of a slight densification; also there are a great contributions as well as transformation of reacted materials into crystalline reaction products (Fig.2b). A significant increase in the matrix porosity was observed after firing at $800^{\circ} \mathrm{C}$ with the presence of wide gaps within the reaction products (Fig.2c), as explained by low matrix cohesion up on high firing temperature which resulted from dehydroxylation of geopolymer network that in turn lead to weakness of its mechanical properties. After firing at $1000^{\circ} \mathrm{C}$, area of low porosity and large pores dominated the matrix (Fig.2d). Development of these large pores is possibly connected to the material decomposition upon heating as well as dehydroxylation of geopolymer composite.

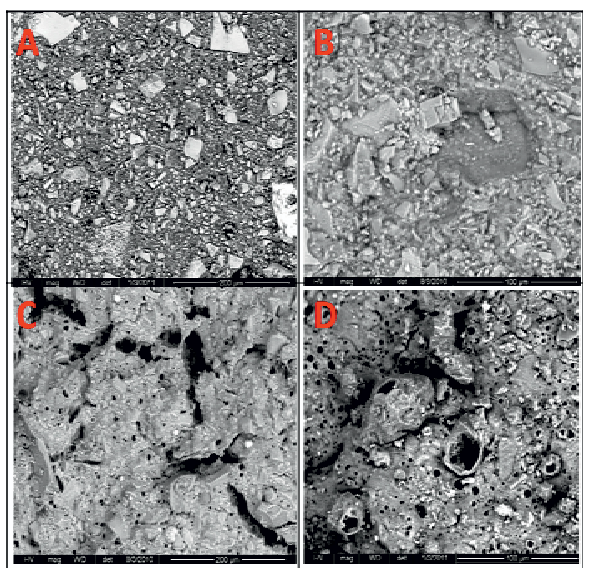

Fig,(2): SEM micrograph of alkali activated specimens using 3:3 sodium hydroxide to sodium silicate having $10 \% \mathrm{SF}$ and $90 \%$ WCS (a) unfired sample, (b) fired at $500^{\circ} \mathrm{C}$, (c) fired at $800^{\circ} \mathrm{C}$ and (d) fired at $1000^{\circ} \mathrm{C}$

Figure 3, depicts the morphology and microstructure of various geopolymer compositions fired at 800 and $1000^{\circ} \mathrm{C}$ for 2 hours with a heating rate of $5^{\circ} \mathrm{C} / \mathrm{min}$. Morphology of SF-geopolymer matrix fired at $800^{\circ} \mathrm{C}$ reflects loose compaction between the geopolymeric matrix and hydration materials resulting from dehydroxylation of geopolymer structure (Fig.3a), whilst the morphology of $15 \%$ ACS and $85 \%$ GGBFS mix specimen implements better geopolymer matrix stability upon firing at $800^{\circ} \mathrm{C}$ with the presence of high geopolymer contribution area, whereas a traceable amount of efflourescence of sodium carbonate spreaded on matrix surface (Fig.3b). Figure (3c), shows the morphology of $25 \%$ ACS geopolymer mix as partial replacement of water cooled slag constituent, where thermal stability decreased up on increasing of air cooled slag, as the higher crystalline content leads to the decrease in amorphous GGBFS content with the increase of air cooled slag.

Increasing firing temperature up to $1000^{\circ} \mathrm{C}$ leads to development of large pores that possibly connected to material decomposition upon heating which accompanied by the increase of average pore size in SF geopolymer mix (Fig.3d), this is will possess a pessimism effect on the matrix stability and hence its mechanical characteristics. Using $15 \%$ ACS (Fig.3e) gives better microstructure characteristics as compared with SF-geopolymer mix. The replacement of GGBFS by $15 \%$ ACS leads to the formation of geopolymer structure that can withstand even at this high temperature and possess a thermal stability higher than that of comparable SF-mix of geopolymer mix contains; this thermal stability can be related to the better rearrangement of geopolymer structure by partial replacement of GGBFS by ACS that results in a formation of compact matrix, where ACS grains are much harder than GGBFS grains if replaced in a lower dose [Heikal et al., (2004)], so this replacement will positively enhance the mechanical and microstructural characteristics upon using $15 \%$ ACS.

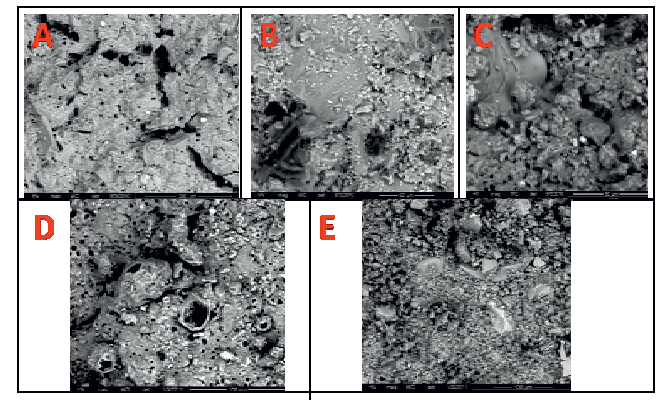

Fig.(3): SEM micrograph of alkali activated specimens using 3:3 sodium hydroxide to sodium silicate (A) $10 \% \mathrm{SF}$ and $90 \% \mathrm{WCS}$ fired at $800^{\circ} \mathrm{C}$, (B) $85 \% \mathrm{WCS}$ and $15 \% \mathrm{ACS}$ fired at $800{ }^{\circ} \mathrm{C}$, (C) $75 \% \mathrm{WCS}$ and $25 \% \mathrm{ACS}$ fired at $800^{\circ} \mathrm{C}$, (D) $10 \% \mathrm{SF}$ and $90 \% \mathrm{WCS}$ fired at $1000^{\circ} \mathrm{C}$, and (E) $85 \% \mathrm{WCS}$ and $15 \%$ ACS fired at $1000^{\circ} \mathrm{C}$

The term fire resistance is frequently used to assess the behaviour after firing of different samples as indicated from (Fig. 4), illustrating strength pattern of geopolymer specimens prepared using 3:3 sodium hydroxides to sodium silicate activator and indicate thermal stability of the geopolymer mixes to firing treatment up to $500^{\circ} \mathrm{C}$ except for mix contains $25 \%$ CKD as compared with concrete specimens prepared and treated at the same conditions. This thermal stability was coincided with previous findings stated that beyond $300^{\circ} \mathrm{C}$, no shrinkage or expansions were recorded until $700^{\circ} \mathrm{C}$. Between $700^{\circ} \mathrm{C}$ and $800^{\circ} \mathrm{C}$, 
further increase in shrinkage was observed. Shrinkage occurred due to mass loss in geopolymer when subjected to elevated temperature [Kong and Sanjayan (2008)].

The figure also illustrates thermal stability of SFmix up to $500^{\circ} \mathrm{C}$ followed by a steep decrease up to $800^{\circ} \mathrm{C}$ which may be connected to a dramatic increase of the average pore size as the amorphous structures were replaced by the crystalline Nafeldspars; that in turn contributed to increase in porosity and strength deterioration [Bakharev (2006)]. This suggests that dehydration causes contraction of the gel resulting in aggregation of pores that can be observed by SEM, (Fig. 2c, d).

Geopolymer mix of $15 \%$ air cooled slag (ACS) exhibits a pronounced withstand to high fire temperature as compared with other mixes up to $1000^{\circ} \mathrm{C}$ and did not exhibit a thermal deterioration as reflected from its morphology (Fig.3b,e). This may be due to the partial replacement of GGBFS by ACS results in a formation of compact matrix, as ACS grains are much harder than GGBFS grains if replaced in a lower dose [Heikal (2004)]. Continuous increase in ACS up to $25 \%$ results in thermal deterioration beyond $800^{\circ} \mathrm{C} \quad$ (Fig.3c), which explained by the increase of crystalline content on the expense of amorphous geopolymer content leading to decrease in thermal stability of the reaction products. It is known that strength and microstructure stability after firing is an indication of good fire resistance in refractory context. While fire resistance in a fireprotection context is based upon heat conduction through a sample when exposed to standard fire defined by Wickström and Hadziselimovic (1996).

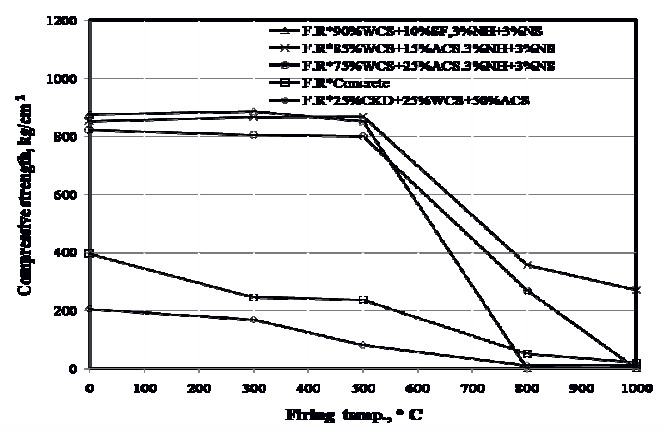

Fig.(4): Compressive strenglh of fircd alkali activated geopolyme specimens at different firing temperatures (using 3:3 sodium hydroxide to sodium silicate).

Adding 25\%CKD along with both air and watercooled slag (GGBFS) implement a lower thermal stability as compared with all other geopolymer mixes and even with concrete specimen. It is possible due to rapid deterioration of materials prepared using $\mathrm{CKD}$ due to lower reaction degree of CKD, incomplete polymerization of geopolymers and because of impurities present in the dust that lowered the melting temperature of these materials [Van Vlack (1964)]. Excess alkalis in CKD especially sodium in addition to the added Na-containing activators have high diffusion coefficient on firing thus lower thermal stability of the matrix. Concrete specimen has lower thermal stability as the geopolymeric cement concrete was superior to Portland cement in terms of heat and fire resistance, where the Portland cement experienced a rapid deterioration in compressive strength at $300^{\circ} \mathrm{C}$, whereas the geopolymeric cement specimens were stable up to $600^{\circ} \mathrm{C}$ as recorded by Davidovits et al., (1994).

\subsection{Acid resistance of geopolymer mixes}

Figure (5) elucidates the visual appearance of geopolymer specimens after soaking in an equimolar ratio of $\mathrm{HCl}$ and $\mathrm{HNO}_{3}$ at a concentration of four molar up to 4 months as compared with concrete mix prepared at the same condition. It can be seen that the SF-geopolymer specimen (Fig.5a) exposed to 4 molars mix of acids undergoes etches at the corner of the cubes and it can be noticed also that this geopolymer mix possess little damage as compared with other specimens, while at later ages suffers from complete deterioration. Geopolymer mix that has 25 $\%$ ACS (Fig. 5b) exposed to surface as well as edges erosion of the cubic specimen. The severity of the damage and distortion of the specimen's shape depended on the concentration of the solution. Where, the mix that has $25 \%$ CKD shows a gelatinous structure reflecting the rapid deterioration and its weak acid resistance (Fig.5d). Concrete specimen on the other hand exhibits deterioration from all sides as well as from the interior of the cubic specimen (Fig. $5 \mathrm{c}$ ), as coincide with low resistivity of concrete structure to acid medium.

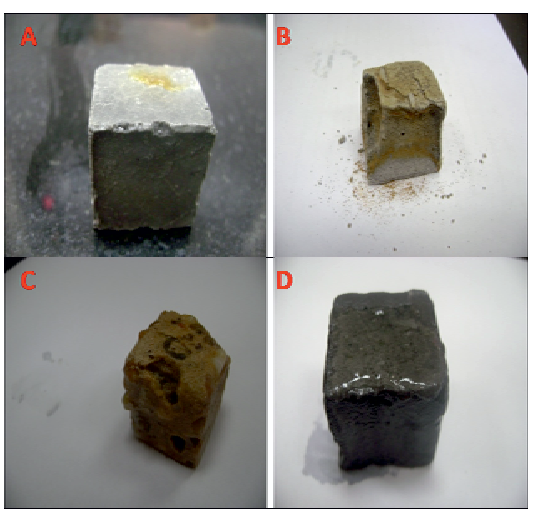

Fig. (5): Visual appearance of geopolymer specimens afler 4 months exposed to 4 molars acid solution of $\mathrm{HCl}_{\mathrm{HNO}}$ in an equimolar ratio (a) $10 \% \mathrm{SF}$ and $90 \%$ WCS, (b) $75 \%$ WCS $+25 \% \Lambda C$, (c) concretc, and(d) $25 \%$ CKD $+25 \%$ WCS and $50 \% \mathrm{ACS}$ 
Figures $(6,7)$ represent compressive strength of the studied geopolymer mixes as well as concrete specimens that exposed to 2, 4 and 6 molars mixed acid solutions, but the patterns of acid resistance are empty from the higher concentration (6M) as all specimens suffers from complete deterioration at the last mentioned concentration. Strength of all mixes decrease with acid concentration increase as well as with curing age. Increase of acid solution higher than $4 \mathrm{~mol} / \mathrm{L}$, leads to a complete deterioration and dissolution of geopolymer mixes. It is known that reaction product of geopolymer is a kind of threedimensional structure in which the tetrahedral $\mathrm{SiO}_{4}$ and $\mathrm{AlO}_{4}$ units are polycondensed with the alkaline ions balancing the charge [Davidovits (1997)]. It is mainly the amorphous analogue of zeolite and feldspar. Although most of alkalis are fixed into the three-dimensional structure, some alkali can remain in soluble form. This free alkali is easily dissolved, which generates an increase in the porosity of the specimen and consequently a decrease in its strength [Alomo et al. (1999)].

Visual examination confirms that SF-mix has higher strength values up to 3 months, while samples suffered from different erosion degrees in different acid solutions as revealed from Figure (5). Increased replacement of GGBFS by $25 \%$ ACS, leads to lowering its resistance as reflected from its strength The increased content of ACS decreases amorphous geopolymer structure that can be reflected on its acid resistance (Fig.6).

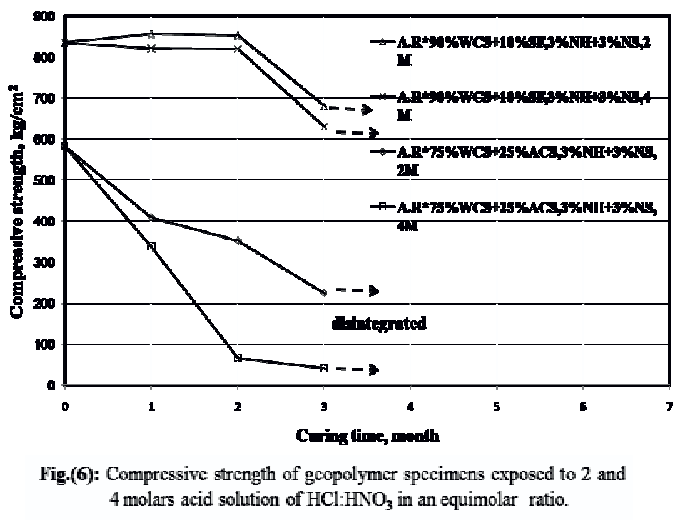

Uses of $25 \%$ CKD provides an extra alkali to the matrix which in turn leads to increase in the average pore size and porosity [Kong et al. (2008)] and so it will be more susceptible to acid penetration and dissolution providing strength value that lowered than the concrete mix which is known by its weak acid resistance (Fig.7). When the $\mathrm{pH}$ value of acid solution decreases, the geopolymer medium will be disturbed and favor the oligomer dissolution than geopolymer formation and precipitation formation. Also, the free alkalis can balance the $\mathrm{H}^{-}$; the compressive strength will not decrease [Wenying et al. (2008)], but when the concentration of $\mathrm{H}^{-}$is higher, many free alkalis react with the $\mathrm{H}$ - and causes strength decrease.

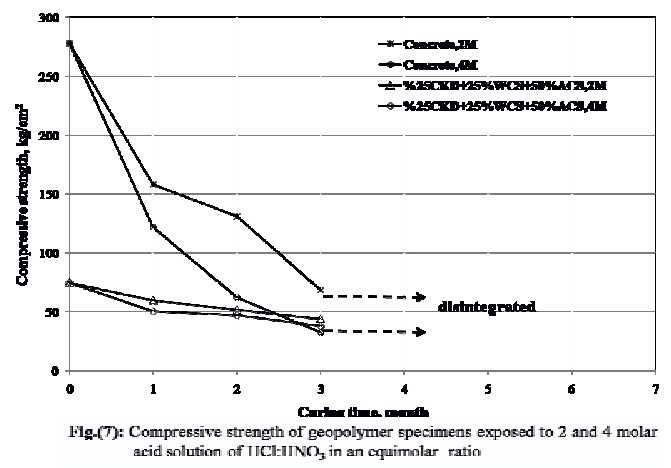

\section{Conclusion}

1- The geopolymer materials prepared with sodiumcontaining activators exhibit thermal stability up to $500^{\circ} \mathrm{C}$ more than that obtained by normal concrete mix specially those contains SF and ACS which could be used in the manufacture of nuclear power plant.

2- Partial substitution of GGBFS by $15 \%$ ACS possesses a thermal stability up to $1000^{\circ} \mathrm{C}$ reflecting the amorphous geopolymer behavior which resists heat treatment and can be used in the refractory bricks. Increasing ACS content to $25 \%$ lowers the thermal stability of geopolymer composition.

3- Partial substitution of GGBFS by $10 \%$ SF with its amorphous structure exhibit thermal stability up to $500^{\circ} \mathrm{C}$ giving strength values that exceed the comparable ACS mixes, but strength diminishes beyond this temperature while ACS mixes resist deterioration up to $800^{\circ} \mathrm{C}$.

4- Most geopolymer mixes as well as concrete specimen have low acid resistance and deteriorated after 3 months of immersion in acids; these were revealed from their loss in strength and were emphasized from the images of the visual examination, where the decreased $\mathrm{pH}$ leads to destabilization and dissolution of geopolymer structure

5- Strength of $25 \%$ air cooled slag mixes decrease up to complete diminishes beyond 3 months, while SF mixes resist acid deterioration up to 2 months providing strength values exceed that of ACS mixes. On the other hand, mixes have $25 \% \mathrm{CKD}$ provide lowest stability up on acid immersion as reflected from their strength values which lowered than that of concrete mixes. 


\section{References}

1. Abd.El-Aziz, H., "Physico-Chemical Studies of Alkali Acivated Slag Pastes", Master Theses, Zagazig University, Zagazig, Egypt,2010.

2. Alomo, A.; Blanco-Varela, M. T.; Puertasa, F.; Vazquez, T.; Grutzeck, M.W.,(1999) "Chemical Stability of Cementitious Materials Based on Metakaolin", Cem. Concr. Res., 29(7); 997-1004.

3. ASTM C109M- 07, "Standard Test Method for Compressive Strength of Hydraulic Cement Mortars", 2007.

4. Bakharev, T.(2005) "Resistance of geopolymer materials to acid attack", Cement and Concrete Research, 35(4), 658-670.

5. Bakharev, T.; Sanjayan, J. G.; Cheng, J. B.,(2003) "Resistance of alkali-activated slag concrete to acid attack. Cement and Concrete Research, 33(10); 1607-1611.

6. Bakharev, T., (2006) "Thermal behaviour of geopolymers prepared using class F fly ash and elevated temperature curing", Cement and Concrete Research, 36(6) ; 1134-1147.

7. Barbosa, V.F.F.; MacKenzie, K.J.D., (2003) "Synthesis and thermal behaviour of potassium sialate geopolymers", Mater. Lett., 57,14771482.

8. Davidovits J.(1997) "Geopolymers: Inorganic Polymeric New Materials”, J. Therm. Anal., 37, 1633-1656.

9. Davidovits, J., "High-Alkali Cements for $21 \mathrm{st}$ Century Concretes". Paper presented at the V. Mohan Malhotra Symposium on Concrete Technology: Past, Present and Future, University of California, Berkeley, 1994a

10. Davidovits, J., "Properties of geopolymer cements, Proceedings First International Conference on Alkaline Cements and Concretes, 1, SRIBM, Kiev, Ukraine, 131-149,1994b.

11. Davidovits, J.; Davidovits, M.; Davidovits, N., "Process for obtaining a geopolymeric aluminosilicate and products thus obtained", US Patent $(5,342,595), 1994$.

12. Douglas, E; Bilodeau, A; Brandstetr, J.; Malhotra, V.M.,(1992) "Properties and durability of alkali-activated slag concrete", ACI Mater J., 89(5), 101-8.

13. Duxson, P.; Fernández-Jiménez, A.; Provis, J.L.; Lukey, G.C.; Palomo, A.; van Deventer, J.S.J., ( 2007) "Geopolymer technology: the current state of the art", J. Mater. Sci. 42, 29172933.
14. El-Sayed, H.A; Abo El-Enein, S.A.; Khater, H.M.; Hasanein, S.A., ( 2011) "Resistance of Alkali Activated Water Cooled Slag Geopolymer to Sulfate Attack", Ceramics - Silikáty, 55 (2), 153-160.

15. Glukhovsky, V.D., "High strength slag alkaline cements". In: Proceedings of the 7th international congress on the chemistry of cement, Paris; 1980.

16. Glukhovsky, V.D.,(1980) "High strength slag alkaline cements", In: Proceedings of the 7th international congress on the chemistry of cement, Paris.

17. Gourley, J. T.; Johnson, G. B., "Developments in Geopolymer Precast Concrete". Paper presented at the International Workshop on Geopolymers and Geopolymer Concrete, Perth, Australia, 2005.

18. Heikal, M.; Radwan, M.M.; Morsy, M.S.,(2004) "Influence of Curing Temperature on the Physicomechanical, characteristics of Calcium Aluminate Cement with Air -Cooled Slag or Water-Cooled Slag", Ceramics - Silikáty ,48 (4), 185-196.

19. Khale, D.; Chaudhary, R.,(2007) "Mechanism of geopolymerization and factors influencing its development: a review”, J. Mater. Sci., 42, 729746.

20. Kong, Daniel L.Y.; Sanjayan, Jay G. (2008) "Damage behavior of geopolymer composites exposed to elevated temperatures", Cement \& Concrete Composites,30, 986-991.

21. Krivenko, P.V.; Kovalchuk, G.Yu.,(2002) "Heat-resistant fly ash based geocements", Proceedings of the Int. Conf. Geopolymer 28th29th October 2002, Melbourne, Australia, 2002.

22. Lyon, R.E.; Balaguru, P.N.; Foden, A.; Sorathia, U.; Davidovits, J.; Davidovits, M., "Fire response of geopolymer structural composites", Proceedings of 1st Int. Conf. Fiber Composites in Infrastructure (ICCI'96), Tuscon, Jan. 15-17, 1996, Dept. Civ. Eng., Univ. of Arizonapp, 972-981,1996.

23. Osborne, G.J., "The sulfate resistance of Portland and blast furnace slag cement concretes". In: Proceeding of second international conference on the durability of concrete, SP-126 Montreal, Canada, 1047-71, 1991.

24. Pal, S.C.; Mukherjee, A.; Pathak, S.R.,(2002) "Corrosion behaviour of reinforcement in slag concrete", ACI Mater J., 99(6); 521-7.

25. Palomo, A.; Grutzeck, M.W.; Blanco-Varela, M.T.,(1999) "Alkali activated fly ashes: a 
cement for the future", Cem. Concr. Res., 29, 1323-1329.

26. Saikia, N.; Usami, A.; Kato, S.; Kojima, T.,(2004) "Hydration behavior of ecocement in presence of metakaolin", resource progressing journal, 51(1), 35-41.

27. Song, S.; Jennings, H.M., (1999) "Pore solution chemistry of alkali-activated ground granulated blast-furnace slag", Cem. Concr. Res., 29, 159170.

28. Song, X. J.; Marosszeky; Brungs, M.; Munn, R., "Durability of fly ash-based Geopolymer concrete against sulphuric acid attack". Paper presented at the 10 DBMC International Conference on Durability of Building Materials and Components, Lyon, France, 2005.

29. Talling, B. Brandstetr J. "Present state and future of alkali activated slag concretes". In: Proceedings of the third international conference on fly ash, silica fume, slag and natural Pozzolans in concrete, Trondheim, SP114-72, 1519-46, 1989.

30. Van Vlack, H., ( 1964 ) "Physical Ceramics for Engineers", Addison-Wesley, London, 94-102, 1964.

31. Wang, S.-D.; Pu, X.C.; Scrivener, K.L.; Pratt, P.L., (1995) "Alkali activated slag cement and concrete: a review of properties and problems", Adv. Cem.Res. 7 (27), 93- 102.

32. Wenying, G.; Guolin, W.; Jianda, W.; Ziyun, W.; Suhong, Y., (2008) "Preparation and Performance of Geopolymers", Journal of Wuhan University of Technology-Mater. Sci. Ed., 23(3), 326-330.

33. Wickström, U.; Hadziselimovic, E.,(1996) "Equivalent concrete layer thickness of a fire protection insulation layer", Fire Saf. J., 26, 295302. 